\title{
OTIMIZAÇÃO DO PROCESSO DE FERMENTAÇÃO SUBMERSA PARA PRODUÇÃO DE XILANASE POR Aspergillus tubingensis AN1257 COM USO DE TORTA DE CAROÇO DE ALGODÃO COMO FONTE DE CARBONO
}

\author{
R. S. SANTOS ${ }^{1,2}$, F.K.P. ALVES ${ }^{3}$, A. P. F. C. VANZELA ${ }^{1,2}$, L. A. PANTOJA ${ }^{1,4}$, A. S. SANTOS ${ }^{1,3}$ \\ ${ }^{1}$ Departamento de Farmácia - Universidade Federal dos Vales do Jequitinhonha e Mucuri - UFVJM \\ ${ }^{2}$ Programa de Pós-graduação em Biocombustíveis - UFVJM, \\ ${ }^{3}$ Departamento de Ciências Básicas - UFVJM \\ ${ }^{4}$ Instituto de Ciências e Tecnologia - UFVJM \\ e-mail para contato: ricardo.santos@ufvjm.edu.br
}

\begin{abstract}
RESUMO - Estudos voltados para o desenvolvimento de processos biotecnológicos que utilizam biomassas residuais vêm sendo amplamente estimulados nos últimos anos. Neste contexto, o presente trabalho teve como objetivo otimizar o processo de produção de xilanase em fermentação submersa utilizando uma linhagem de Aspergillus tubingensis e torta de algodão como fonte de carbono. A otimização da produção da enzima acima foi realizada por aplicação de uma metodologia de superfície resposta. O extrato enzimático foi caracterizado quanto aos parâmetros de temperatura e $\mathrm{pH}$ ótimos, bem como sua estabilidade frente a essas variáveis . A condição ideal para a produção de xilanase foi de $1,25 \%$ de torta de algodão num meio líquido contendo $0,9 \mathrm{~g} / \mathrm{L}$ de $\mathrm{NH}_{4} \mathrm{NO}_{3}$, após 101 horas de fermentação, a qual exibiu valores de $42 \mathrm{U} / \mathrm{mL}$ de atividade xilanolítica. No que diz respeito à caracterização bioquímica da atividade xilanolítica foi possível observar uma temperatura ótima de $55^{\circ} \mathrm{C}$ e pH ótimo próximo de 4,0 , condição a qual a atividade xilanolítica observada foi de $76,4 \mathrm{U} / \mathrm{mL}$.
\end{abstract}

\section{INTRODUÇÃO}

Existe uma variedade de micro-organismos, incluindo bactérias, leveduras e fungos filamentosos com potencial elevado para produzir enzimas lignocelulolíticas. Os fungos filamentosos, como os gêneros Aspergillus e Trichoderma têm demonstrado um grande interesse biotecnológico devido à capacidade para secretar uma vasta gama de celulases e xilanases, com características físicoquímicas variadas e com potenciais excelentes para a aplicação industrial, bem como a capacidade de síntese em grande escala e facilidade com que são secretadas para o meio externo (Iwashita, 2002; Papagianni, 2004; Gottschalk et al., 2010). No entanto, algumas espécies promissoras na produção de hidrolases, como o Aspergillus tubingensis, ainda são pouco estudadas e relatadas na literatura (Bakri et al., 2010, Shimokawa et al., 2012, Pandya et al., 2012).

Deve-se salientar a composição dos meios de fermentação contribui consideravelmente para o preço final do produto, tornando-se necessário a busca de substratos de baixo custo para o processo 


\section{9 a 22 de outubro de 2014 \\ Florianópolis/SC}

fermentativo (Fachinni et al., 2011, Pandya et al., 2012). A tendência de estudos em desenvolver processos biotecnológicos que permitam a utilização de biomassas residuais, de composição lignocelulósica, como palha de milho, trigo e arroz, serragem, bagaço de cana-de-açúcar, resíduos da indústria de celulose, co-produtos da cadeia de biodiesel, etc., abundantemente geradas nos setores agrícolas e florestais, tem sido relatada há alguns anos (Vásquez et al. 2007, Pereira Jr. et al., 2008, Balat, 2011, Limayem et al., 2012). A utilização destas biomassas como fonte de carbono nas fermentações por fungos filamentosos é uma estratégia economicamente promissora, na qual além agregar valores à coprodutos de baixo valor agregado, levará a uma redução de custo no processo de produção de enzimas hidrolíticas.

Neste contexto, o presente trabalho teve por objetivo: otimizar as condições de cultivo de uma linhagem isolada de Aspergillus tubingensis AN1257 em fermentação submersa (FSb) para produção de xilanase, utilizando torta de caroço de algodão como fonte de carbono e caracterizar bioquímicamente o extrato enzimático produzido quanto à temperatura e $\mathrm{pH}$ ótimos.

\section{METODOLOGIA}

\subsection{Obtenção do material de estudo: torta de algodão e linhagem Aspergillus tubingensis}

A torta de algodão utilizada neste estudo foi doada pela Indústria de Óleo, Rações e Plásticos Montes Claros LTDA - Montes Claros - MG. Esta biomassa foi inicialmente triturada em moinho manual e em seguida submetida a um processo de extração lipídica, por extração com éter etílico, para eliminação de óleo residual, posteriormente, seca a $60^{\circ} \mathrm{C}$, por período de 48 horas.

O micro-organismo avaliado neste trabalho, Aspergillus tubingensis AN1257, é uma linhagem de ocorrência natural, isolado a partir de estudos de triagem. Esta linhagem foi mantida no Laboratório de Bioprocessos e Biotransformação - UFVJM, estocada em tubos de ensaio contendo meio BDA (Agar Batata Dextrose). Para manutenção, foram realizados repiques periódicos (a cada 3 meses) sendo as culturas mantidas $30^{\circ} \mathrm{C}$ durante 7 dias (PDA) e conservada sob refrigeração $\left(4 \pm 1^{\circ} \mathrm{C}\right)$.

\subsection{Otimização do processo de fermentação submersa}

A condição ótima para a produção de xilanase pela linhagem Aspergillus tubingensis AN1257 foi investigada pelo emprego de um planejamento experimental do tipo composto central rotacional (CCR), com dois níveis e três fatores, seis pontos axiais e quatro centrais (Tabela 1). Os fatores analisados foram o tempo de fermentação (horas), a concentração da torta de algodão (fonte de carbono) e concentração de $\mathrm{NH}_{4} \mathrm{NO}_{3}$ (fonte de nitrogênio). O software STATISTICA Versão 7.0 foi utilizado para geração e análise destes planejamentos experimentais. A qualidade do ajuste da equação de cada modelo foi expressa pelo coeficiente de determinação $\left(R^{2}\right)$ e sua significância estatística condicionada pelo teste- $F$. Os resultados do processo de otimização foram expostos em gráficos de superfície resposta.

Os ensaios fermentativos do processo de otimização (Tabela 1) foram realizados em frascos 
Erlenmeyer de $125 \mathrm{~mL}$, em triplicata, contendo $25 \mathrm{~mL}$ meio líquido de fermentação composto de $\mathrm{NaCl}(0,1 \mathrm{~g} / \mathrm{L}), \mathrm{MgSO}_{4}-7 \mathrm{H}_{2} \mathrm{O}(0,2 \mathrm{~g} / \mathrm{L}), \mathrm{KH}_{2} \mathrm{PO}_{4}(0,4 \mathrm{~g} / \mathrm{L}), \mathrm{K}_{2} \mathrm{HPO}_{4}(0,1 \mathrm{~g} / \mathrm{L})$. O inóculo utilizado nos ensaios foi preparado a partir do repique da cultura estoque de Aspergillus tubingensis AN1257 em meio sólido Vogel (VOGEL, 1964) contido em placas de Petri e incubadas a $30^{\circ} \mathrm{C}$ por 7 dias. Os conídios foram coletados assepticamente em $10 \mathrm{~mL}$ de água destilada estéril, filtrados através de gaze e contados em câmara de Neubauer para determinação da concentração. A suspensão de conídios utilizada em todos os pontos experimentais foi inoculada de forma a obter uma concentração final de $1,0 \times 10^{5}$ conídios/mL de meio líquido de fermentação.

Os processos fermentativos foram conduzidos a $30^{\circ} \mathrm{C}$ em estufa incubadora, sob agitação a 150 rpm. A obtenção dos extratos enzimáticos foi realizada por meio de filtração em funil de Büchner à vácuo utilizando papel de filtro com retenção de partículas de 7 a $12 \mu \mathrm{m}$. O filtrado foi mantido em gelo até a determinação da atividade xilanásica. A atividade xilanásica foi realizada por quantificação de açúcares redutores (Miller, 1959) liberados após 10 minutos em um meio reacional contendo 1:1 de extrato enzimático e xilana de Birchwood $1 \%$, a $50^{\circ} \mathrm{C}$ e $\mathrm{pH} 5$. A unidade de xilanase $(\mathrm{U} / \mathrm{mL})$ foi definida como sendo a quantidade de enzima capaz de liberar $1 \mu \mathrm{mol}$ de açúcares redutores, por minuto, por volume (mililitros) de extrato enzimático.

Tabela 1 - Planejamento experimental Composto Central Rotacional (CCR), com dois níveis e três fatores (tempo, concentração da torta de algodão e concentração da fonte de nitrogênio)

\begin{tabular}{|c|c|c|c|c|c|}
\hline Fatores & $-\alpha(-1,29)$ & $\mathrm{N}(-1)$ & $\mathrm{PC}(0)$ & $\mathrm{N}(+1)$ & $+\alpha(+1,29)$ \\
\hline $\mathrm{X}$ - Tempo (horas) & 11,15 & 48,0 & 96,0 & 168,0 & 180,85 \\
\hline $\mathrm{Y}-$ Algodão (\%) & 0,189 & 0,5 & 1,25 & 2 & 2,311 \\
\hline $\mathrm{Z}-\mathrm{NH}_{4} \mathrm{NO}_{3}(\mathrm{~g} / \mathrm{L})$ & 0,193 & 0,4 & 0,9 & 1,4 & 1,607 \\
\hline
\end{tabular}

PC: Ponto central, N: Nível

\subsection{Caracterização bioquímica}

Efeito da temperatura sobre a atividade enzimática: A temperatura ótima de ensaio enzimático foi definida através da dosagem da atividade da enzima xilanase, a partir do extrato enzimático produzido em condições ótimas, sob diferentes temperaturas, 20, 30, 40, 50, 60, 70, 80 e $90^{\circ} \mathrm{C}$.

Efeito do $\mathrm{pH}$ sobre a atividade enzimática: A influência do $\mathrm{pH}$ na atividade xilanásica foi determinada por meio da quantificação da atividade desta enzima, utilizando como substrato a Xilana de Birchwood dissolvida em tampão McIlvane, em diferentes pHs (3, 4, 5, 6, 7 e 8), sob temperatura ótima previamente definida.

\section{RESULTADOS E DISCUSSÕES}

\subsection{Otimização do processo de fermentação submersa}

Após análise do modelo matemático, com base nos resultados expressos na tabela 2, observouse que ajuste feito pelo programa estatístico, representado por $\mathrm{R}^{2}(0,82750)$ foi satisfatório. Utilizando 
a análise de variância (ANOVA; Tabela 2) pode-se observar os efeitos quadráticos significativos ( $\mathrm{p} \leq$ $0,05)$ de todas as variáveis (torta, tempo e nitrogênio). Além disso, interações significativas entre quaisquer variáveis não foram verificados para qualquer grupo de enzimas produzidas. Ao considerar que a falta de ajuste não foi significativa ( $\mathrm{p}>0,05$ ), o que, combinado com os valores de $\mathrm{F}$ e os valores dos coeficientes de determinação $\left(\mathrm{R}^{2}\right)$, pode-se inferir que o modelo se ajusta adequadamente aos pontos experimentais, representando a confiabilidade dos resultados.

Tabela 2. Valores da análise de variância (ANOVA) para os modelos polinomiais de segunda ordem, e coeficientes

\begin{tabular}{|l|c|c|c|c|c|}
\hline \multicolumn{1}{|c|}{$\begin{array}{c}\text { Fonte de } \\
\text { Variação }\end{array}$} & $\begin{array}{c}\text { Soma dos } \\
\text { quadrados }\end{array}$ & $F$ & $p$ & Efeitos & Coeficiente \\
\hline Tempo (horas)(L) & 51,255 & 5,0432 & 0,046236 & X & $-2,0696$ \\
\hline Tempo (horas)(Q) & 1719,826 & 169,2216 & 0,000000 & X2 & $-14,3661$ \\
\hline Torta \%(L) & 958,093 & 94,2712 & 0,000001 & Y & 8,9354 \\
\hline Torta \%(Q) & 350,887 & 34,5254 & 0,000107 & Y2 & $-6,6326$ \\
\hline NH4NO3 g/L(L) & 26,243 & 2,5822 & 0,136372 & $\mathrm{Z}$ & 1,4788 \\
\hline NH4NO3 g/L(Q) & 224,726 & 22,1118 & 0,000648 & Z2 & $-5,3077$ \\
\hline
\end{tabular}

Os gráficos de superfície de resposta representados na figura 1 ilustram o perfil da influência das concentrações de torta de algodão, fonte de nitrogênio e tempo de fermentação. Foi possível observar os efeitos quadráticos negativos e a condição onde uma maior atividade enzimática foi obtida, ou seja, uma condição ótima. Resultados como este também podem ser observados em estudos realizados por Alam et al., (2008) e Zimbardi et al., (2013). Além disso, ao analisar os gráficos em duas dimensões das figuras supracitadas, observou-se uma ampla faixa cuja atividade máxima é obtida. Este perfil demonstra que a produção enzimática apresenta uma elevada robustez, ou seja, pequenas variações não alteram o resultado final do processo, uma característica valorosa para processos de produção a nível industrial.

O extrato enzimático produzido pela linhagem Aspergillus tubingensis AN1257, utilizando $1,25 \%$ de torta de algodão e $0,9 \mathrm{~g} / \mathrm{L}$ de nitrato de amônio no período de 101 horas de fermentação submersa, apresentou valores de atividade xilanásica de $42 \mathrm{U} / \mathrm{mL}$. Com base nos valores dos coeficientes expostos na Tabela 2, o modelo matemático de produção de xilanase pode ser representado pela equação: Xilanase $(\mathrm{U} / \mathrm{mL})=38,57-2,07 \mathrm{X}+8,93 \mathrm{Y}+1,49 \mathrm{Z}-14,37 \mathrm{X}^{2}-6,63 \mathrm{Y}^{2}-$ $5,31 Z^{2}$. 


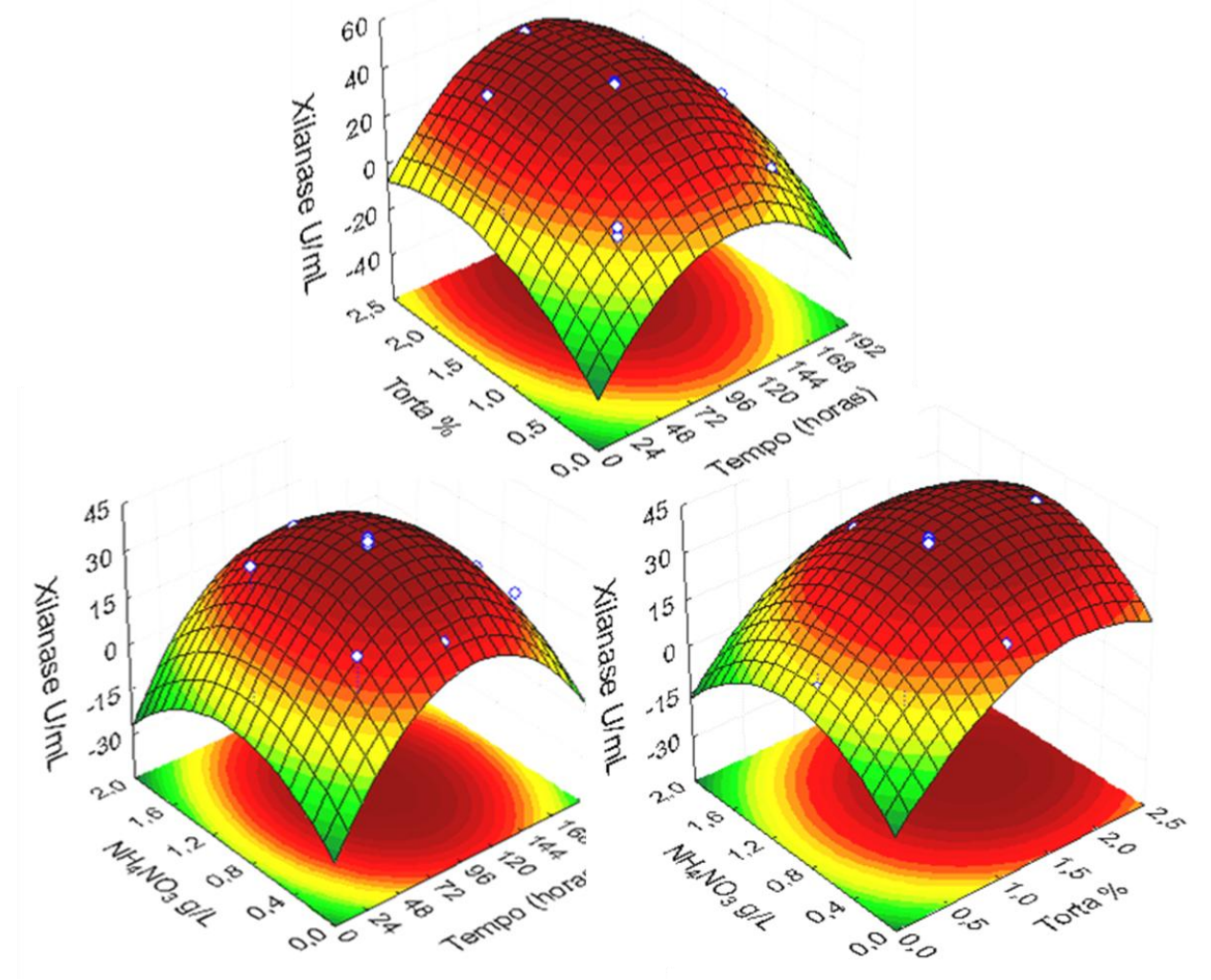

Figura 1 - Gráficos de superfície resposta dos efeitos combinados Torta (\%), Fonte de Nitrogênio $\left(\mathrm{NH}_{4} \mathrm{NO}_{3}-\mathrm{g} / \mathrm{L}\right)$ e Tempo (horas) nas atividades de xilanase

\subsection{Caracterização bioquímica}

Efeito da temperatura sobre a atividade enzimática: Os resultados, expressos graficamente na Figura 2, demonstram que a temperatura ótima de atuação da enzima xilanase foi entre 50 e $60^{\circ} \mathrm{C}$, atingindo valores de atividade próximos a $45 \mathrm{U} / \mathrm{mL}$. Esta faixa de temperatura foi similar à encontrada por Bakri et al. (2010). Tais resultados denotam uma boa aplicabilidade industrial destas enzimas sob temperaturas relativamente altas.

Efeito do $\mathrm{pH}$ sobre a atividade enzimática: Os resultados relacionados ao efeito do $\mathrm{pH}$ na atividade da enzima xilanase encontram dispostos na Figura 2. Estes resultados evidenciaram que o pH ótimo de atividade xilanásica é em torno de 4,0, dados estes, contrário a alguns estudos reportados na literatura, que geralmente, preconizam $\mathrm{pH}$ em torno de 5,0 para enzimas produzidas por Aspergillus sp. (Bakri et al., 2010; Fachinni et al., 2011; Gomathi et al., 2012). Este fato deve-se, provavelmente, a características fisiológicas do micro-organismo, que varia de acordo com o ambiente e condições nutricionais existentes. Outro fato que subsidia esta ideia, refere-se aos efeitos dos pHs observados durante o crescimento da linhagem de Aspergillus tubingensis AN1257, que decaiu bruscamente de 6,0 para 2,5 (Santos, 2012). Os dados apresentados na Figura 2, permite inferir que a atividade enzimática determinada em $\mathrm{pH} 4,0$ quando comparada com a determinada em pH 5,0 apresenta um aumento de $60 \%$ na atividade da 
enzima xilanase. $\mathrm{O}$ valor máximo de atividade xilanásica, determinada em $\mathrm{pH}$ 4,0 (condição ótima de atuação) foi de $76,4 \mathrm{U} / \mathrm{mL}$.

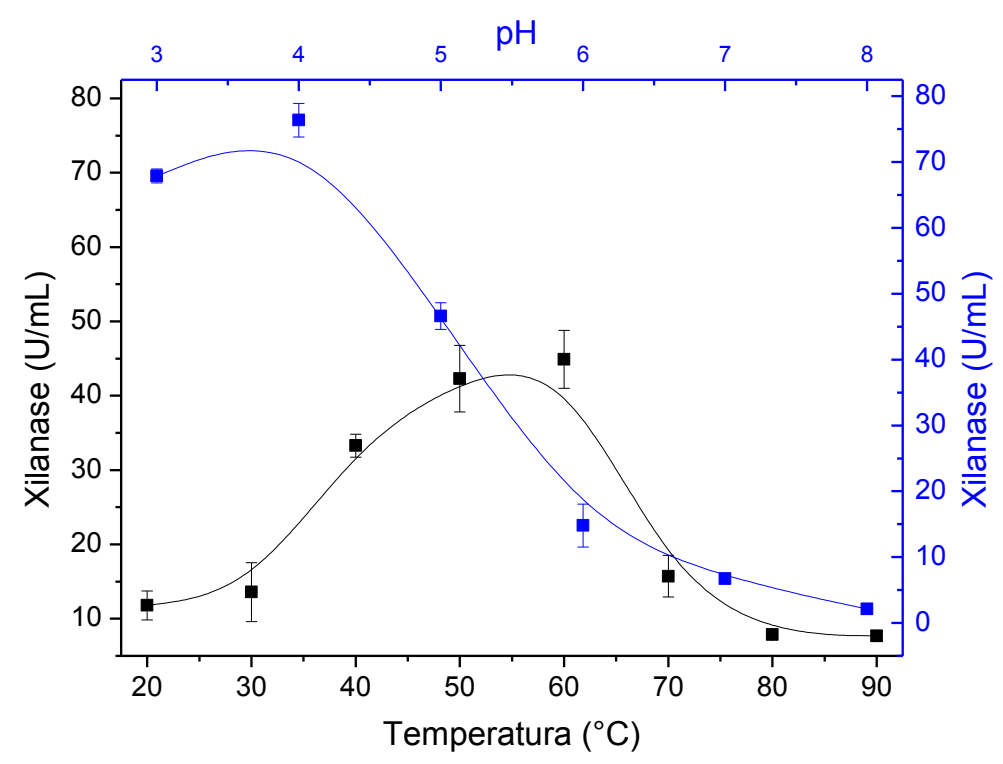

Figura 2 - Efeito da temperatura (linha preta) e pH (linha azul) sobre a atividade de xilanase produzida por A. tubingensis AN1257, utilizando torta de algodão como fonte de carbono.

\section{CONCLUSÕES}

O estudo realizado e seus dados obtidos permitiram concluir que apesar das enzimas xilanases serem comumente comercializadas, há necessidade de estudos voltados para sua produção a fim de torná-las mais acessíveis e com baixo custo. Sendo assim, este trabalho contribuiu de forma positiva na obtenção de dados científicos relevantes para o crescimento deste cenário. A utilização de resíduos provenientes da extração lipídica de oleaginosas, oriundos da cadeia de produção do biodiesel, como fonte de carbono em processos de fermentação por fungos filamentosos se mostrou relevante para produção de endoglucanase, por agregar valor a co-produtos subutilizados, bem como pela sua eficiência quando utilizado como substratos em processos fermentativos. A utilização de modelos estatísticos aplicadas a estudos de produção de enzimas xilanolíticas se mostrou eficiente por possibilitar a obtenção de resultados otimizados em processos fermentativos de forma confiável e rápida. A pesquisa realizada gerou perspectivas de novos estudos relacionados ao aproveitamento de resíduos da cadeia do biodiesel para a produção de hidrolases xilanolíticas por processos de baixo custo.

\section{REFERÊNCIAS}

ALAM, M.Z.; MUHAMMAD, N.; MAHAMAT, M.E. Production of cellulase from oil palm biomass as substrate by solid state bioconversion. Am. J. Appl. Sci. v. 2, p. 569-572, 2005.

BAKRI Y.; MASSON M.; THONART P. Isolation and Identification of Two New Fungal Strains for 


\section{9 a 22 de outubro de 2014 \\ Florianópolis/SC}

Xylanase Production. Appl Biochem Biotechnol 162:1626-1634, 2010.

BALAT, M. Production of bioethanol from lignocellulosic materials via the biochemical pathway: A review. Energy Conv and Management, v. 52, p. 858-875, 2011.

FACCHINI, F. D. A.; VICI, A. C.; BENASSI, V. M.; FREITAS, L. A. P.; REIS, R. A.; JORGE, J. A.; TERENZI, H. F.; POLIZELI M. L. T. M. Optimization of fibrolytic enzyme production by Aspergillus japonicus $\mathrm{C} 03$ with potential application in ruminant feed and their effects on tropical forages hydrolysis. Bioprocess Biosyst Eng, 2011.

GOTTSCHALK, L. M. F.; OLIVEIRA, R. A.; BOM, E. P. S. Cellulases, xylanases, -glucosidase and ferulic acid esterase produced by Trichoderma and Aspergillus act synergistically in the hydrolysis of sugarcane bagasse. Biochem. Eng. J. 51, p. 72-78, 2010.

IWASHITA, K. Recent studies of protein secretion by filamentous fungi. J Biosc Bioeng, v. 94, n. 6, p. 530-535. 2002.

LIMAYEM, A.; RICKE, S. C. Lignocellulosic biomass for bioethanol production: Current perspectives, potential issues and future prospects. Progress in Energ and Combust Sci, v. 38, p. 449 $-467,2012$.

MILLER, G. L. Use of dinitrosalicylic acid reagent for determination of reducing sugar. Anal. Chem., v.31, p.426-428, 1959.

PANDYA, J. J.; GUPTE, A. Production of xylanase under solid-state fermentation by Aspergillus tubingensis JP-1 and its application. Bioprocess Biosyst Eng, 35: p. 769-779, 2012.

PAPAGIANNI, M. Fungal morphology and metabolite production in submerged mycelia processes. Biotech. Adv., v. 22, p. 189-259, 2004.

PEREIRA Jr., N.; COUTO, M. A. P. G.; SANTA ANNA, L. M. M. Biomass of lignocellulosic composition for fuel ethanol production and the context of biorefinery. In Series on Biotechnology, Ed. Amiga Digital UFRJ, v.2, p. 45, 2008.

SANTOS, R. S. Produção de enzimas celulolíticas e xilanolíticas por fungos filamentosos utilizando resíduos da cadeia do biodiesel como fonte de carbono. Dissertação (Mestrado em Química) Faculdade de Ciências Exatas, Diamantina: UFVJM, 107 p. 2013.

SHIMOKAWA, T.; SHIBUYA, H.; ISHIHARA M.; YAMAGUCHI M.; OTA Y.; MIYAZAKI, K.; IKEDA, T.; MAGARA, K.; NOJIRI, M.. Screening of lignocellulolytic enzyme producers: enzyme system from Aspergillus tubingensis for hydrolysis of sugi pulp. Bulletin of FFPRI, vol.11 No.2 (No.423), p. $57-63,2012$.

VÁSQUEZ, M.P.; SILVA, J. N. C.; DE SOUZA JR., M.B.; PEREIRA JR., N. Enzymatic hydrolysis optimization to ethanol production by Simultaneous Saccharification and Fermentation. Applied Biochem \& Biotech, v. 12, p. 137-140, 2007.

VOGEL, H. F. Distribution of lysine pathways among fungi: evolutionary implications. AmerNaturalist, v. 98, p. 435-446, 1964.

ZIMBARDI, A. L. R. L.; SEHN , C.; MELEIRO L.P.; SOUZA, F. H. M.;. MASUI D. C.; NOZAWA M. S. F.; GUIMARÃES L. H. S.; JORGE J. A.; FURRIEL R. P. M. Optimization of $\beta$-Glucosidase, $\beta$-Xylosidase and Xylanase Production by Colletotrichum graminicola under Solid-State Fermentation and Application in Raw Sugarcane Trash Saccharification. Inter J of Molec Sci., v. 14, p. 2875-2902, 2013. 